\title{
Hypothesis
}

\section{HHV-8 in multiple myeloma: is this the first paracrine model of human tumorigenesis and do Koch's postulates apply?}

\author{
J J O’Leary, I Silva, V Uhlmann, M Prasad, K Luttich, A Maffei, S Picton
}

\begin{abstract}
Department of Pathology, Cornell University Medical College, 1300 York Avenue, New York, NY 10021, USA

I Silva

M Prasad

A Maffei

Department of Pathology, Coombe Women's Hospital, Dolphin's Barn,

Dublin 8, Ireland

J J O'Leary

V Uhlmann

K Luttich
\end{abstract}

Perkin Elmer Applied Biosystems, Kelvin Close, Birchwood

Science Park,

Warrington, Cheshire

WA3 7PD, UK

$S$ Picton

Correspondence to: Dr O'Leary.

Accepted for publication 21 May 1998

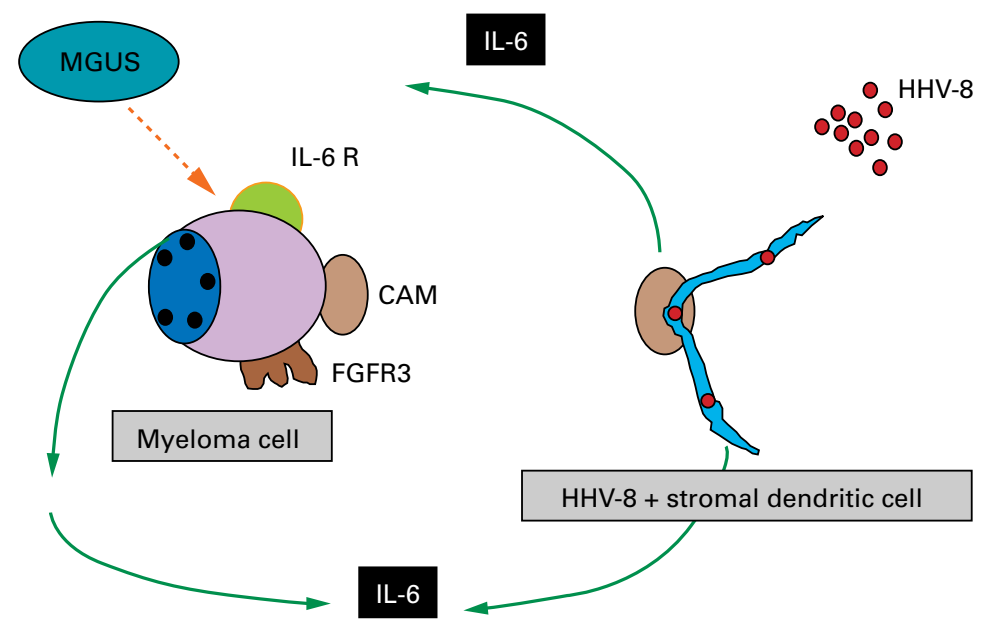

Figure 1 Schematic diagram of the possible role of $H H V-8$ in the pathogenesis of intramedullary multiple myeloma. The model assumes the existence of a premalignant population of cells (MGUS; monoclonal gammopathy of uncertain significance). $H H V-8$ colonises dendritic reticulin cells in the bone marrow, with subsequent upregulation of $H H V-8$ v-IL-6 production. This interacts with the IL-6 receptor (IL-6 R) on the surface of a plasma cell. The plasma cell is also equipped with the fibroblast growth factor 3 receptor (FGFR3). The result is a paracrine loop of v-IL-6 production, which promotes plasma cell tumour growth.

Human herpesvirus 8 (HHV-8) is now clearly implicated in the pathogenesis of Kaposi's sarcoma. ${ }^{1-6} \mathrm{HHV}-8$ is also implicated in the pathobiology of effusion lymphoma ${ }^{7}$ and, recently, we and others have demonstrated this virus in effusion and non-effusion multiple myeloma, ${ }^{8-10}$ in pyothorax associated lymphoma, and in Castleman's disease. ${ }^{11} \mathrm{HHV}-8$, a $\gamma$-II herpes virus, is unique in that it carries 16 different genes important in inflammation, the cell cycle, and apoptosis, including orf 16 (a bcl-2 homologue), viral interleukin 6 (v-IL-6), v-cyclin, vMIP I, and vMIP II. ${ }^{12}$ vMIP I and vMIP II are inflammatory macrophage proteins, with sequence similarity to the human CC chemokines.

IL-6 is a growth factor for multiple myeloma. ${ }^{13}$ Indeed, it has been shown that transgenic $\mathrm{C} 57 \mathrm{BL} / 6$ mice, which express an immunoglobulin enhancer activated IL-6 gene, polyclonal benign plasmacytosis. Interestingly, this strain is resistant to experimental plasmacytoma induction. In the context of the susceptible BALB/c strain, IL-6 transgenic mice develop malignant, monoclonal plasmacytomas that carry a rearranged 
and secretion of viral and human proteins (HHV-8 v-IL-6 and its human homologue, HHV-8 vMIP I, and HHV-8 vMIP II) might stimulate myeloma growth and predispose cells to secondary genetic alterations that ultimately result in the development of a clone capable of rapid expansion and accumulation. In essence, in intramedullary sites, $\mathrm{HHV}-8$ might act as the viral "paracrine drive" for malignant plasma cells. Recently, we have shown that in effusion myeloma, malignant plasma cells are infected with $\mathrm{HHV}-8,{ }^{9}$ and HHV-8 encoded products (v-IL-6, vMIP I, and vMIP II) might act as an "autocrine drive".

While this is an attractive hypothesis, it is currently the subject of much speculation and investigation. Rettig and colleagues ${ }^{8}$ identified HHV-8 in all cultured bone marrow stromal/ dendritic cells from patients with multiple myeloma but not in the malignant plasma cell population. Ten out of 15 of these patients were untreated. Importantly, HHV-8 was not identified in bone marrow stromal cell DNA from 16 patients with other malignancies, including two cases of Hodgkin's disease and 12 cases of nonHodgkin's lymphoma, or in 10 normal controls. In situ hybridisation localised HHV-8 in bone marrow stromal cells. Using a reverse transcription polymerase chain reaction (RT-PCR) assay, the authors identified HHV-8 v-IL-6 transcripts in three of three bone marrow stromal cell samples from patients with myeloma.

Recently, the same group has identified HHV-8 orf 72 DNA sequences in bone marrow biopsies by in situ hybridisation. Eighteen of 21 patients with multiple myeloma harboured HHV-8 sequences, as did two of two patients with AIDS associated plasmacytosis, and one of three patients with monoclonal gammopathy of undetermined significance. Six of seven fresh multiple myeloma bone marrow core biopsies contained HHV-8 DNA sequences. Again, the normal control and haematological malignancy cohort $(n=25)$ did not contain HHV-8. These results exclude an "artefact" result in cultured dendritic cells.

Recently, we have reported localisation of HHV-8 in seven of 12 fresh multiple myeloma biopsies, using real time Taq Man quantitative PCR and PCR in situ hybridisation (PCRISH) to orf 26 (major capsid protein), v-cyclin, and v-IL-6 encoding regions. ${ }^{9}$ We have confirmed the observation by Rettig et al of HHV-8 localisation in a minority cell population (dendritic cells) in bone marrow isolates. The copy number of HHV-8 in these lesions is low and we have convincingly demonstrated HHV-8 v-IL-6 production as well as vMIP I and vMIP II. In contrast, effusion myelomas contain higher quantities of HHV-8 as assessed by Taq Man PCR and quantitative competitive PCR.

A larger study of patients with multiple myeloma has recently reported finding HHV-8 in 32 of 74 patients. ${ }^{16}$ Similar results have also been reported by others. ${ }^{10}$

\section{Evidence against $\mathrm{HHV}-8$ in the} pathobiology of multiple myeloma

Several groups have raised questions regarding the infection of bone marrow dendritic cells in multiple myeloma. Much of the controversy has emanated from serological studies. Parravicini and colleagues have recently examined a series of 40 Italian patients with multiple myeloma, using a sensitive nested PCR assay and a serological assay to HHV-8 latency associated nuclear antigen (LANA) and orf 65 lytic genes. ${ }^{17}$ They identified antibodies against HHV-8 in only one of 20 patients. Concomitantly, they examined the antibody status to cytomegalovirus and hepatitis B, which showed positive serology in 18 of 20 and eight of 20 patients, respectively. Whitby and colleagues ${ }^{18}$ used immunoflourescence antibody screening against HHV-8 LANA-1 to test blood donors and patients with multiple myeloma, Hodgkin's disease, and non-Hodgkin's lymphoma. Their results show $11 \%$ positivity in multiple myeloma patients, $5 \%$ positivity in patients with monoclonal gammopathy of undetermined significance, $17 \%$ positivity in patients with Hodgkin's disease, $13 \%$ positivity in patients with non-Hodgkin's lymphoma, and $13 \%$ positivity in blood donors. Other researchers have also questioned the association between HHV-8 and multiple myeloma. ${ }^{19} 20$

\section{Unifying hypotheses}

Clearly, a discrepancy exists between the serological and PCR assay results. The lack of serological evidence for HHV-8 in multiple myeloma might relate to a change in B cell ontogenicity. Patients with multiple myeloma have panhypogammaglobulinaemia, which could potentially reduce the titre of HHV-8 specific antibodies. However, the same should apply for all other viruses, which has not been shown to be the case. ${ }^{17}$ More importantly, however, might be the copy number of HHV-8 infection in patients with multiple myeloma. We have shown that the copy number in these patients is low (1-10 copies/1000 bone marrow cells). ${ }^{21}$ DNA loading experiments have shown a predicted increase in HHV-8 viral DNA copy number, with greater numbers of bone marrow cells examined. In multiple myeloma, neither the precise number of dendritic cells remaining in the neoplastic marrow or what proportion of these cells are infected with HHV 8 are known. We speculate that the numbers of individual dendritic cells infected with HHV-8 are low, and that the copy number of virus in any individual cell is between 1-3 copies, as assessed by PCR-ISH. ${ }^{21}$ Under such circumstances, it is not entirely surprising to find that HHV-8 serology may be negative. In contrast, in effusion related myelomas, a high copy number of $\mathrm{HHV}-8$ is found, akin to effusion lymphomas (Tsang et al 1998, unpublished data).

Negativity for HHV-8 with solution phase PCR poses a problem. Heparin used in bone marrow biopsy samples inhibits Taq polymerase, so that when heparin treated samples are examined, heparinase should also be used. Secondly, polymorphisms within the KS Bam 330 regions at priming sites might account for some negative PCR results. It also appears that one specific strain of HHV-8 might be selectively involved in the pathogenesis of multiple myeloma. 
Clearly, HHV-8 in multiple myeloma does not satisfy Koch's postulates, as is found for most infectious organisms identifed by molecular biological assays. There are now several excellent models available for the propagation of HHV-8 in culture and recently we have shown that HHV-8 can serially infect endothelial cells. ${ }^{24}$

In relation to HHV-8, we need to clarify further the exact prevalence of HHV-8 in multiple myeloma series from disparate geographical areas and gain more detailed sequence data on possible polymorphisms. In addition, the effect of treatment needs to be investigated urgently, as this could potentially alter the HHV-8 copy number. More importantly, HHV-8 viral DNA and the absolute expression profile of HHV-8 v-IL-6, vMIP I, and vMIP II in dendritic cells isolated from multiple myeloma cells need to be measured, and the effects of multiple myeloma proteins on HHV-8 copy number and expression profiles also need to be investigated. Finally, if $\mathrm{HHV}-8$ is involved in a proportion of cases of multiple myeloma, then the effect of antiviral treatments, such as Foscarnet, which have dramatic influences on the outcome of Kaposi's sarcoma need urgent evaluation.

In summary, the jury is still out on the role of HHV-8 in multiple myeloma. However, we might be looking at the first example of a paracrine/autocrine model of viral carcinogenesis in humans.

Dr J J O'Leary is in receipt of a grant from the Irish Cancer Society.

1 Chang Y, Cesarman E, Pessin MS, et al. Identification of herpes-like DNA sequences in AIDS-associated Kaposi's sarcoma. Science 1994;266:1865-9.

2 Boshoff C, Schulz TF, Kennedy M, et al. Kaposi's sarcomaassociated Herpesvirus infects endothelial and spindle cells. Nat Med 1995;1:1274-8.
3 O'Leary JJ. Seeking the cause of Kaposi's sarcoma. Nat Med 1996;2:862-3.

4 Boshoff C, Talbot S, Kennedy M, et al. HHV8 and skin cancers in immunosuppressed patients. Lancet 1996;347: 338-9.

5 O'Leary JJ, Kennnedy MM, McGee JO'D. Kaposi's sarcoma associated herpes virus (KSHV): epidemiology, molecular biology and tissue distribution. $\mathcal{F}$ Clin Mol Pathol 1997;50:4-8.

6 Kennedy M, Picton S, Howells D, et al. KSHV in female Kaposi's sarcoma. F Pathol 1997;183:447-52.

7 Cesarman E, Chang Y, Moore P, et al. Kaposi's sarcoma associated herpesvirus-like DNA sequences in AIDSrelated body-cavity-based lymphomas. N Engl f Med 1995; 332:1186-91.

8 Rettig MB, Ma HJ, Vescio RA, et al. Kaposi's sarcoma associated Herpesvirus infection of bone marrow dendritic cells from multiple myeloma patients. Science 1997;276:1851-4.

9 O'Leary JJ, Silva I, Uhlmann V, et al. Identification of HHV 8 viral DNA sequences in multiple myeloma-implication for disease pathogenesis. F Pathol 1998;184 (suppl):8A.

10 Brousset P, Meggetto F, Attal M, et al. Correspondence. Science 1997;278:1972.

11 O'Leary JJ, Kennedy M, Boshoff C, et al. KSHV in Castleman's disease: evidence for angiogenesis. F Pathol 1997; 180(Suppl):11A.

12 Russo JJ, Bohenzky RA, Chien MC, et al. Nucleotide sequence of the Kaposi's sarcoma associated herpes virus (HHV 8). Proc Natl Acad Sci USA 1997;93:14862-7.

13 Kishimoto T, Akira S, Taga T. Interleukin 6 and its receptor: a paradigm for cytokines. Science 1992;258:593-7.

14 Suematsu S, Matsusaka T, Matsuda T, et al. Generation of plasmacytomas with the chromosomal translocation $\mathrm{t}(12$; plasmacytomas with the chromosomal translocation t(12; 232-5.

15 Bataille R, Harousseau JL. Multiple myeloma. New Engl f Med 1997;336:1657.

16 Alkan S, Dahiya M, Hsi ED, et al. Detection of Kaposi's sarcoma associated herpes virus/ human herpes virus 8 in multiple myeloma patients. Proceedings of The AmericanCanadian Acadamy of Pathology 1998:726A.

17 Parravicini C, Lauri E, Baldinin L, et al. Kaposis's sarcomaassociated Herpes virus infection and multiple myeloma. associated Herpes virus

18 Whitby D, Boshoff C, Luppi M, et al. Kaposis's sarcomaassociated Herpes virus infection and multiple myeloma. Science 1997;278:1971-2.

19 MacKenzie J, Sheldon J, Morgan G, et al. HHV 8 and multiple myeloma in the UK. Lancet 1997;350:1144-5.

20 Marcelin AC, Dupin N, Bouscary D, et al. HHV 8 and multiple myeloma in France. Lancet 1997;350:1144.

21 O'Leary JJ, Silva I, Uhlmann V, et al. In-vitro and in-vivo evidence of a viral "hit and run" phenomenon in HHV 8 induced vascular tumours. $\mathcal{F}$ Pathol 1998. [In press.]

22 Flore O, Rafii S, Hyjek E, et al. HHV 8 can infect and transform primary endothelial cells. Nature 1998. [In press.] 